\title{
COMUNIDADES QUILOMBOLAS DE SANTARÉM: A FORÇA FEMININA
}

\section{Renata Priscila Benevides De Sousa ${ }^{1}$ Anne Caroline Fernandes Alves ${ }^{2}$}

\section{Resumo:}

O presente artigo insere-se em um contexto analítico que busca compreender os processos de resistência das Comunidades Quilombolas de Santarém - PA, através da força feminina, envolvendo o elo histórico entre as subjetividades coletivas, abrangendo a relação dos atores sociais com a sua história, crenças, práticas ancestrais de existência, resistência e reexistência, diante do avanço da fronteira do agronegócio. A reconstrução dos lugares e dos papéis da mulher quilombola santarena revela um processo de resistência de gênero dentro das Comunidades e da Federação Quilombola, por meio da solidariedade entre as mulheres, que protagonizaram mobilizações para ampliação dos padrões de reconhecimento.

Palavras-chave:

Comunidades Quilombolas; Santarém; Força feminina;Gênero;Reconstrução.

\section{QUILOMBOLAS COMMUNITIES OF SANTAREM: A FEMALE FORCE}

\begin{abstract}
:
The present article is inserted in an analytical context that seeks to understand the resistance processes of the Quilombola Communities of Santarém - PA, through the female force, involving the historical link between collective subjectivities, covering the relationship of social actors with their history, beliefs, ancestral practices of existence, resistance and reexistence, before the advance of the agribusiness frontier. The reconstruction of the places and roles of quilombola santarena women reveals a process of gender resistance within the Communities and the Quilombola Federation, through solidarity among women, who led mobilizations to broaden recognition patterns.
\end{abstract}

Keywords:

Quilombola Communities Santarém female strength genre reconstruction

\section{INTRODUÇÃO}

O presente artigo trata da (re) construção da identidade feminina quilombola de Santarém, caracterizada pela luta junto aos movimentos sociais em prol de reconhecimento e efetividade de direitos das comunidades.

Santarém é uma cidade localizada à margem direita do Rio Tapajós, na região do Baixo Amazonas, no oeste do Estado do Pará ${ }^{1}$, com aproximadamente 370 mil habitantes ${ }^{2}$. Está relativamente próxima à foz do rio Madeira $^{3}$, o que permite uma boa integração com

\footnotetext{
${ }^{1}$ Mestre em Direito Agrário - Universidade Federal de Goiás - UFG (2018). Docente na UNAMA/Santarém. Renatabenevides@hotmail.com

2 Mestre em História pela Pontifícia Universidade Católica de Goiás. Docente no UNIALFA/Goiás. Prof.annecarolinefernandes@gmail.com
} 
outros estados amazônicos, como Rondônia e Amazonas.

A discussão sobre a construção da identidade quilombola em Santarém - PA- é a problemática que se impõe entre a perspectiva de um "progresso" e a luta pelo reconhecimento de direitos das comunidades quilombolas que vivem no local.

Durante o processo de formação social brasileira é sabido que todas as regiões tiveram suas sociabilidades determinadas pela escravidão. O Brasil foi um dos primeiros territórios no mundo a introduzir um regime escravocrata e o último a aboli-la (MAESTRI, 2014). Por escravidão, tomaremos a definição apresentando pela Liga das Nações e pela própria Organização das Nações Unidas que diz ser "o estado ou a condição de indivíduo sobre o qual se exercem, total ou parcialmente, alguns ou todos os atributos do direito de propriedade." (SCOTTI, p.130, 2013).

A diversidade das africanidades, semeadas em cada região brasileira (WALKER, 2001), permite analisar a construção da identidade afro-brasileira, além do simples fato de se saber como e onde aportaram, no Brasil, o contingente de africanos escravizados, quantos eram e de onde vieram, quem eram, quantos aqui nasceram e casaram, quantos morreram e em que trabalhavam. "A cor logo se tornou um marcador social fundamental; as categorizações, fluidas, variavam com o tempo e com o lugar, além de delimitarem classificações sociais e de status." (SCHARCZ, p. 71, 2015).

Para entender os escravismos no Brasil, é necessário se despir das generalizações enraizadas por conceitos estáticos tendo em vista que

\footnotetext{
${ }^{1} \mathrm{O}$ Território Baixo Amazonas abrange uma área de 317.273,50 $\mathrm{Km}^{2}$ e é composto por 12 municípios: Alenquer, Almeirim, Belterra, Curuá, Faro, Juruti, Monte Alegre, Óbidos, Oriximiná, Prainha, Santarém e Terra Santa. Disponível em:<http://www.territoriosdacidadania.gov.br>. Acesso em: outubro de 2016.

${ }^{2}$ Dados do ano de 2016, extraídos do Instituto Brasileiro de Geografia e Estatística - IBGE. Disponível em: <http://www.cidades.ibge.gov.br/xtras/perfil.php?lang=\&codmun=150680 >.Acesso em: out. de 2016.

${ }^{3} \mathrm{O}$ rio Madeira é um rio da bacia do rio Amazonas que banha os estados de Rondônia e do Amazonas. É um dos afluentes principais do rio Amazonas.
} 
Uma especificidade ali resultou de uma atividade econômica predominante, acolá da origem dos escravos, de sua demografia, das demandas do mercado externo e do interno, de fatores ecológicos, das condições africanas de oferta de cativos, dos preços do açúcar no mercado europeu, ou mesmo do incalculável coeficiente de paciência humana quando escravos disseram não às condições a que estavam submetidos etc. (KLEIN; LUNA, 1991).

A diversidade de identidades afro-brasileiras não exclui a procedência das raízes da África. Nesse sentido, Sheyla Walker (2001) defende a presença da diáspora africana em toda a América e em todos os americanos, da Argentina ao Canadá. Essa raiz africana na identidade dos afro-brasileiros permite sua reinvenção nas diversas regiões, podendo ser identificado o afro-mineiro, o afro-nordestino, o afro-sulista, o afro-amazônida (GONZALEZ, 1988).

Dito isso, é preciso destacar que o agronegócio avança suas fronteiras na região norte do país, desconsiderando qualquer modo de viver que não corresponda ao modelo de mercado e consumo hegemônico. A questão agrária permeia a pauta de discussões dos quilombolas que, a cada dia, sofrem com a especulação imobiliária e expropriação territorial, pois Santarém virou uma cidade com um potencial de escoamento da produção de soja da região norte e centro-oeste.

É nesse cenário de enfrentamentos pela existência, resistência e reconhecimento de direito que as mulheres quilombolas assumem lideranças nas suas Comunidades, na Federação Quilombola de Santarém, nos Conselhos Municipais.

\section{REFERENCIAL TEÓRICO: NA RAÇA E NA COR - A FORÇA DAS AFRO- AMAZÔNIDAS}

"Eu moro no lado de lá, é no lado de lá, na beira do rio

Amazônas. Ô neguinho pega a canoa, que eu já quero atravessar, quero voltar antes do vento espertar. Lá vem o navio rema ligeiro, rema ligeiro, eu tenho medo do banzeiro."

(Música "Beira do rio", de Ana Cleide da Cruz Vasconcelos, a Cleide do Quilombo Arapemã) 
Nas reuniões da Federação das Organizações Quilombolas de Santarém - FOQS a pauta do movimento de mulheres é uma constante. Dentro da espacialidade, de construção e reconstrução de identidade quilombola santarena, insurge a luta feminina para contribuir com o debate sobre as contradições de sua autodefinição e lugar nos movimentos sociais.

Durante o ano de 2017, foi gestada e produzida a série "Na raça e na cor", com o objetivo de visibilizar a resistência das Comunidades Quilombolas do Brasil, através da discussão sobre territorialidade, raça e gênero, com um pouco de sua trajetória.

Organizadas pela Federação das Organizações Quilombolas de Santarém - FOQS, Coordenação Nacional de Articulação das Comunidades Negras Rurais Quilombolas CONAQ $^{5}$ e Terra de Direitos, as mulheres promoveram uma série de atividades, como palestras e oficinas com assistentes sociais e psicólogas, a fim de fortalecer a luta de suas comunidades pelo reconhecimento e efetivação de seu direito ao território, bem como pelo reconhecimento de seu papel nesse cenário.

Os debates e rodas de conversa começaram após um trabalho individual de assistência com as psicólogas, pois o silêncio de muitas mulheres refletia o medo de se posicionar sobre o tema, ainda delicado em algumas Comunidades, que trata da força da mulher e de rompimento de paradigmas.

Para o projeto ter êxito, as oficinas se estenderam por todas as 12 Comunidades abordando temas que incentivaram à reflexão sobre os direitos das mulheres, como: violência doméstica, empoderamento feminino, a luta feminina no movimento social.

\begin{abstract}
E assim, eu acho que depois dessas oficinas que nós tivemos, as mulheres adquiriram ... elas tiveram novo horizonte, porque elas estavam muito focada em ..."Ah o meu marido manda, e eu tenho que obedecer e assim que tem que ser e eu não tenho que retrucar nem nada". E depois das oficinas, nó temos uma experiência que pra nós já valeu tudo que as mulheres já passaram. Nós tinha uma colega, do Quilombo do Arapemã, que era espancada todo final de semana pelo marido e então pra gente já valeu, porque depois das oficinas, depois que ela começou participar, ela na verdade se conheceu e descobriu que ela tinha direitos. Que direito não é só dizer "eu tenho uma casa", não é só direito à moradia, também é direito a ser respeitada, que o corpo era dela, que ela podia fazer o que ela quisesse com o corpo dela (Claudina, Conselheira de Saúde FOQS) .
\end{abstract}

\footnotetext{
${ }^{4}$ Ver em <http://naracaenacor.terradedireitos.org.br/manifesto/>. Acesso em mar. de 2018.

${ }^{5}$ Criada no dia 12 de maio de 1996, em Bom Jesus da Lapa na Bahia, após a realização da reunião de avaliação do I Encontro Nacional de Quilombos, tem como objetivo lutar pela garantia de uso coletivo do território, pela implantação de projetos de desenvolvimento sustentável, pela implementação de políticas públicas levando em consideração a organização das comunidades de quilombo; por educação de qualidade e coerente com o modo de
} 
viver nos quilombos; o protagonismo e autonomia das mulheres quilombolas; pela permanência do (a) jovem no quilombo e acima de tudo pelo uso comum do Território, dos recursos naturais e pela em harmonia com o meio ambiente. Disponível em: <http://conaq.org.br/nossa-historia/>. Acesso em: mar. de 2018. 
A violência sofrida por algumas mulheres das Comunidades Quilombolas difere-se da violência sofrida pela mulher urbana ao passo que o grito de ajuda, em uma comunidade ribeirinha ou rural, demora muito mais tempo para chegar a ser ouvido do que o pedido de socorro de uma mulher que está na cidade, em função da falta de estrutura, telefone, energia e instrução.

Das experiências dessas mulheres que avançam no debate sobre territorialidades e fortalecem os processos políticos de suas comunidades através da perspectiva do combate ao racismo e sexismo (GONZALES, 1984), a série propõe uma mobilização, a partir das experiências do movimento quilombola da região, narradas durante atividades em grupo, viabilizando a construção da identidade étnica e de gênero, individual e coletiva (THOMPSON, 2001).

O deslocamento do papel da mulher, na luta pelos direitos de sua Comunidade, implica em uma mudança de responsabilidade, eminentemente doméstica, quebrando paradigmas e assumindo os espaços de liderança política (BARGAS; CAL, 2017). Espaços públicos que só recentemente tem sido ocupados pelo feminino em função da noção histórica e socialmente construída acerca do lugar da mulher, o privado, o doméstico (SCOTT, 1995).

$\mathrm{Na}$ Federação da Organização dos Quilombolas de Santarém, atuam como presidentes e cargos de confiança, de Comunidades, cinco mulheres: Dona Cleide (Presidente da Comunidade Quilombola Arapemã), Dona Claudiana (Secretária da FOQS e Conselheira Municipal de Saúde), Dona Lídia (Secretária da FOQS e Presidente da Comunidade Quilombola do Maicá e Conselheira Municipal de Transportes), Dona Ivone e Dona Juscimara (Presidentes da Comunidade Quilombola Saracura).

As presidentes têm a função de representar sua Comunidade nas reuniões semanais da Federação levando suas demandas para serem discutidas e informando as decisões que foram tomadas pelo grupo.

\footnotetext{
A presidente tem poder de decisão dentro de seu quilombo. Tem por obrigação repassar as demandas elencadas nas reuniões da Federação, quais os encaminhamentos que nós tivemos, se terá reunião no Ministério Público se tem audiência no INCRA. Todas essas coisas são repassadas para a comunidade. A federação representa as 12 comunidades e cada comunidade tem sua obrigação, por isso toda segunda-feira a gente se reúne aqui pra que a gente possa fazer essas demandas (Claudina, Conselheira de Saúde FOQS).
}

As secretárias têm a responsabilidade do registro das atas e de participar de todas as reuniões, mas não têm o poder de decisão, mesmo na ausência dos presidentes das 
Comunidades e da Federação. 
A gente vai participar da reunião, vai descrever tudo, mas a gente não tem o poder de decisão. Se a gente fizer qualquer coisa, no caso assim, qualquer coisa que a gente colocar no documento, que não seja do agrado do Presidente, ele vai poder retrucar e poder retirar, porque não temos poder de decisão (Claudina, Conselheira de Saúde FOQS).

As conselheiras representam a FOQS e suas demandas nos Conselhos Municipais de Saúde e Transporte e dedicam maior parte do seu tempo entre as atividades da Federação, das Comunidades e do Conselho, conflitando muitas vezes com a imposição da atividade doméstica imposta por alguns homens das Comunidades.

O debate sobre o lugar da mulher no processo de construção de identidade de um povo, assim como os diferentes modos de integração do seu papel no seio das comunidades, revela a necessidade das afro-amazônidas estarem sempre inseridas na luta por melhores condições de existência e reconhecimento.

A mulher negra sempre necessitou estar inserida na luta por melhores condições de existência e isto se dava através de diversas formas de organização, desde o período escravista, no pós-abolição e até os dias atuais, com organizações que nem sempre se acomodaram nos moldes formais, mas que sempre foram constantes (ALMEIDA, 2010, p. 3).

Essa luta indica uma linha crescente na participação das mulheres das Comunidades Quilombolas nas demandas políticas e sociais do movimento. Claudiana Souza, representante da FOQS no Conselho Municipal de Saúde de Santarém, explica que, apesar da conquista da liberdade frente ao escravismo, em uma época de punições cruéis, ainda há muito a se conquistar pelo reconhecimento dos direitos dos quilombolas.

\begin{abstract}
Sempre eu via fotos na minha casa..., eram fotos tipo desenhadas, do meu tataravô com meu pai, aí eu ficava perguntando pro meu pai, meu pai já participava de alguns movimentos, e aí sempre como movimento quilombola, aí um dia eu fui perguntar pro meu pai, porque que nós era quilombola? Ai ele foi me mostrar os retratos pintados de antigamente, que meu tataravô, ele ainda participou de um processo de escravidão muito, muito cruel, que os braços dele tinha as marcas, ainda daquelas algemas que usava com aquelas pedras, [...] isso é muito triste, porque hoje nós não passamos por esse processo, mas de uma certa forma agente se sente apreendido ainda por causa da nossa cor, as pessoas parece que acham que porque é preto, e é parente dos nossos antepassados de escravos, eles tem uma concepção que nós, apesar dos tempos terem passados, parece que nós não conseguimos avançar muito referente a isso, nas nossas políticas pública, voltada pra gente (Documentário Guerreiras Quilombolas Amazônidas).
\end{abstract}

A importância do autoreconhecimento quilombola é, para Claudiana, uma forma de 
não negar suas raízes, uma marca que lembra o sofrimento ancestral, porém, que afirma o seu 
poder de luta e resistência, pois, hoje, ela lembra que seu passado pode ter sido escravo, mas o seu presente é livre.

Eu me autodeclarei, porque eu acredito, se meu tataravô..., sou um fruto lá de trás, uma sementinha lá de trás, e as fotos que meu pai tinha, era umas fotos assim [...] de muito sofrimento, as costas lambadas, com aqueles cortes, aquelas cicatrizes, de muitos tempos neh? ficava aquelas cicatrizes feias na costa, isso pra mim, foi uma coisa assim, que marcou muito minha vida, minha juventude, e hoje quando às vezes, as pessoas dizem assim: "olha tu nasceu preta tu é escravo!", aí eu digo mas eu já fui liberto", eu cantei o "livre estou"!

É o resgate das memórias de um tempo de escravidão, de resistência e de luta que traz à tona o debate da reafirmação da identidade quilombola, retratado pela força dos sujeitos que romperam com a condição que lhes foi cruelmente imposta, resistindo aos instrumentos de dominação e castigo, para conquistar e construir seu próprio modo de viver socialmente, exigindo reconhecimento e os direitos dele advindos. O conhecer e reconhecer sua própria história ocasiona uma consciência histórica que nada mais é que a produção de sentido. Para Rüsen (2007) é o movimento da reflexão sobre a experiência da mudança no tempo, de uma volta ao passado, que permite entender o presente e, possivelmente, orientar-se e projetar-se para o futuro.

Se a gente procurar o conhecimento de onde veio nossas raízes, a nossa história, a gente se fortalece. Mais é muito difícil da gente mesmo se reconhecer por causa do preconceito que tem, e a gente recebe tiro de tudo quanto é lado, até no jeito de olhar. (Lídia Roberta, Quilombo do Arapemã, documentário Guerreiras Quilombolas Amazônidas). 


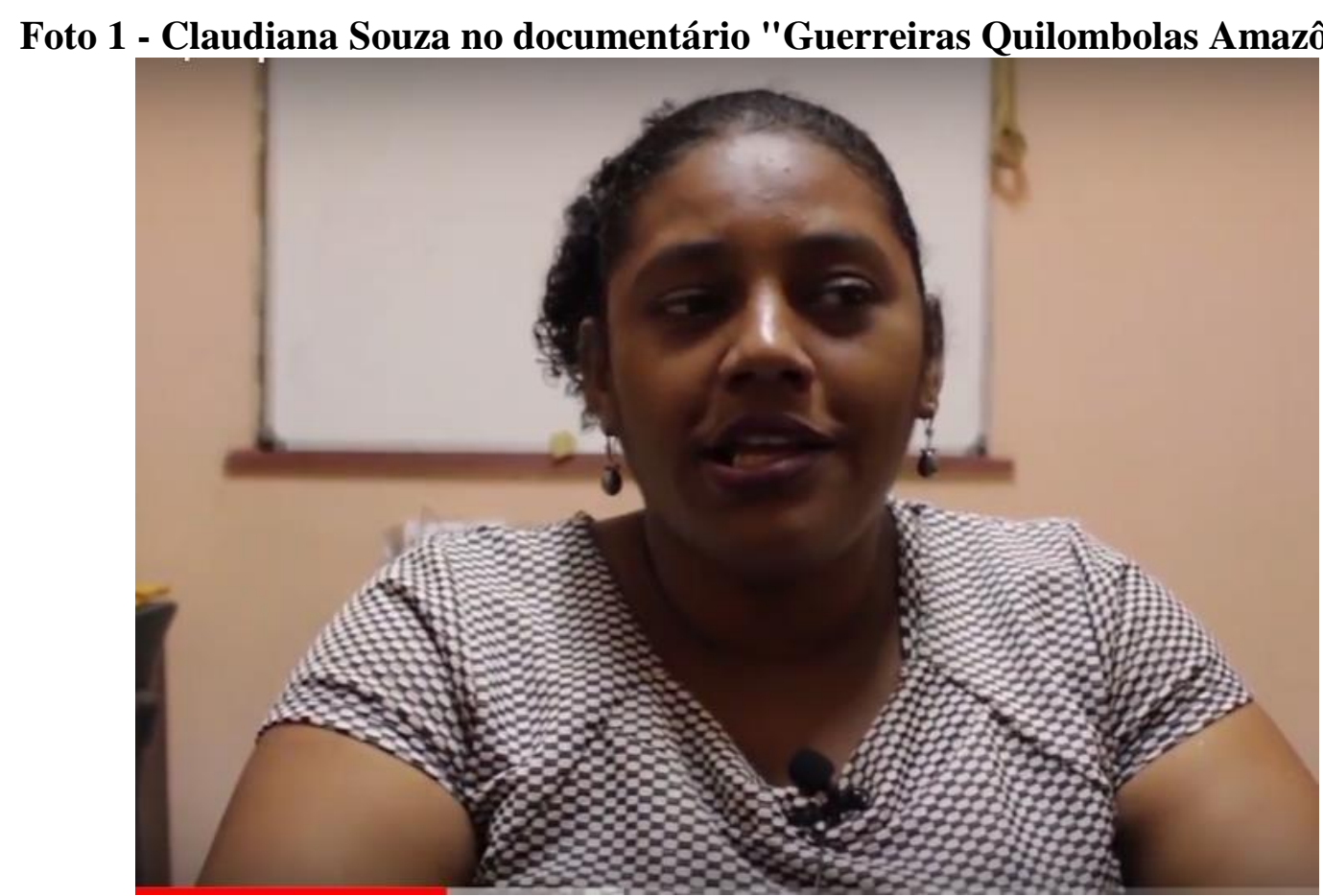

Fonte: "Guerreiras Quilombolas Amazônidas."”

A luta pelo autoreconhecimento da mulher quilombola tem uma dimensão ampla, desde reivindicações sobre o movimento quilombola em geral, como também, os enfrentamentos cotidianos contra o sexismo no meio da vida doméstica e nos movimentos sociais que desafiam a busca pelo questionamento dos lugares tradicionalmente atribuídos às mulheres na condução de demandas do próprio movimento (BARGAS; CAL, 2017).

Para as mulheres quilombolas de Santarém, além do desafio de superar a resistência de negação de seu passado, devem ser superadas as contradições e desigualdades do próprio movimento, o que demanda uma ampliação desta luta, com capacidade de apreender, diante dessa dinâmica social, os antagonismos presentes da opressão sexista (ALMEIDA, 2010).

O estímulo ao debate contra o racismo e contradições, presentes na relação entre gêneros, permite levar a questão da mulher quilombola afro-amazônida para outra perspectiva, além do discurso que a reduz ao papel da "mulata", "doméstica" ou "mãe preta".

Além das lutas pela reafirmação da identidade quilombola e, por consequência, dos seus direitos, a equidade de gênero é uma necessidade latente das guerreiras amazônidas. A resistência da mulher quilombola é ampliada diante da necessidade do rompimento das 
${ }^{6}$ Documentário. Disponível em: <http://naracaenacor.terradedireitos.org.br/>. Acesso em: mar. de 2018.

${ }^{7}$ Nesse sentido, Lélia Gonzales (1984), argumenta e critica a posição da mulher negra como objeto, a mulata inventada pelo português como mercadoria e a simbologia sensual do corpo em detrimento da sua favelização social. 
amarras do preconceito dentro e fora da comunidade, que possuem estrutura reconhecida na diferença das relações de gênero, e incluem hierarquias claras de prestígio entre a masculinidade e a feminilidade (SEGATO, 2012).

É possível afirmar que a afro-amazônida santarena tem consciência de sua importância no fortalecimento do movimento quilombola, ganhando cada vez mais espaço na militância. Durante o ano de 2017, a atuação das mulheres se fez presente nas manifestações contra a $\mathrm{ADI} \mathrm{n}^{\circ} 3239$, como resultado do embate que pretendia questionar a efetivação do processo de reconhecimento e titulação dos quilombolas, dos mocambeiros, e todos os atos administrativos dele decorrentes.

O que queremos é titulação, titular, titular meu irmão, nosso pedaço de chão, titular, titular, meu irmão, nosso pedaço de chão.

(Música “Titulação”, de Ana Cleide da Cruz Vasconcelos, a Cleide do Quilombo Arapemã).

A gente sem-terra, nós não somos nada, uma hora eles dizem que vai sair a titulação, duas horas fala que não vai sair.

(Jolene da Silva, Bom Jardim - documentário Guerreiras Quilombolas

Amazônidas).

Sem ele, todas as nossas conquistas que é direito, que tá garantido na nossa constituição, sem ele é a perda né? De todas essas conquistas.

(Valéria Carneiro, Coordenadora Malungo, sobre a ADI - documentário Guerreiras Quilombolas Amazônidas).

O nosso território está em jogo, o território é nossa vida, é onde criamos nossos filhos, é onde nós plantamos é onde nós vivemos.

(Rejane Maria, CONAQ - documentário Guerreiras Quilombolas Amazônidas).

Diante do cenário de incertezas, montado pela ADI $\mathrm{n}^{\circ} 3239$, o movimento quilombola santareno e nacional se mobilizou para garantir seu direito constitucional historicamente construído. As mulheres quilombolas, do "na raça e na cor," reunidas no encontro de mulheres quilombolas do Baixo Amazonas, em Santarém-PA, nos dias 8 e 9 de julho de 2017, discutiram e elaboraram uma carta que foi encaminhada aos ministros do STF. 


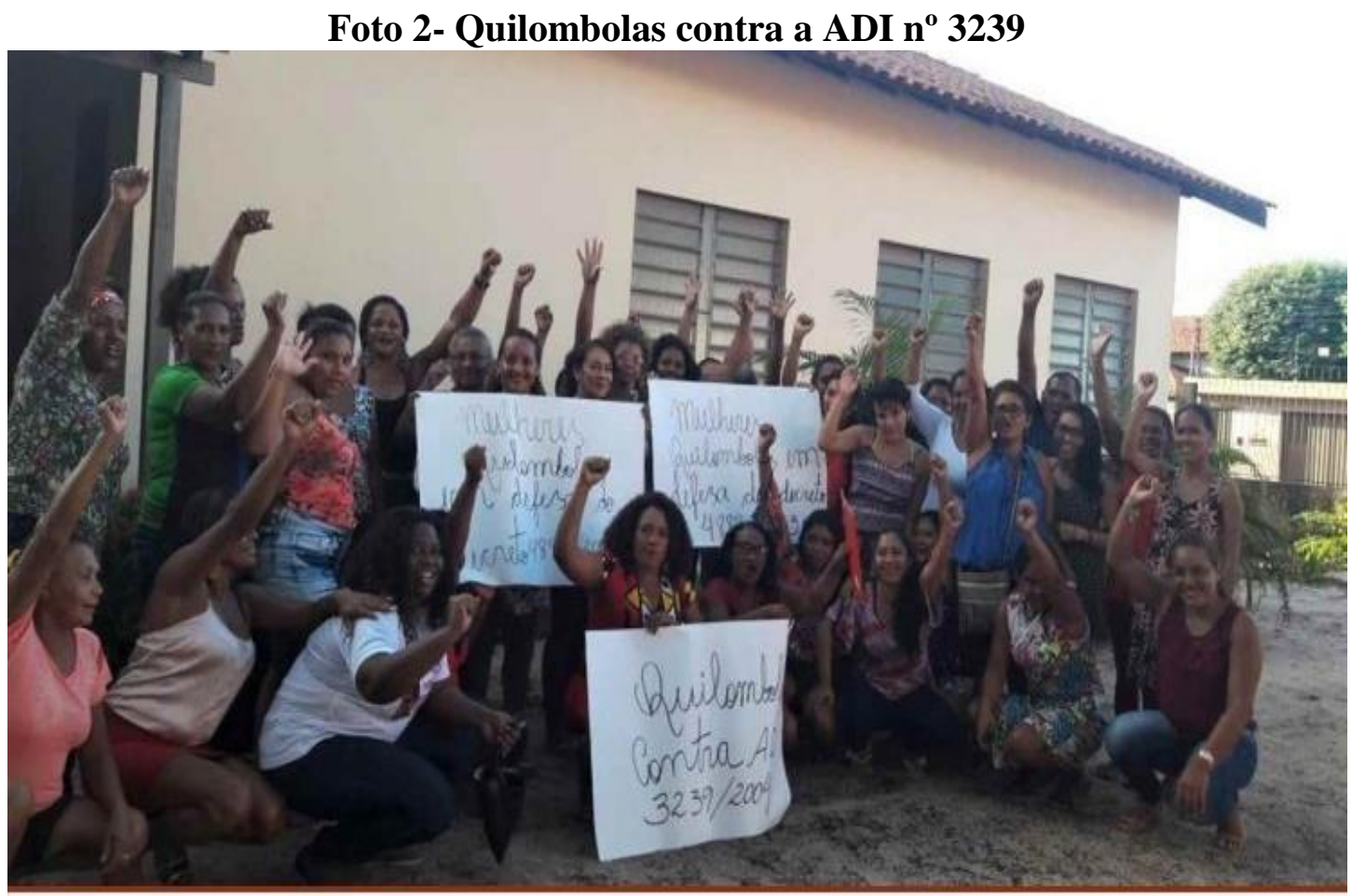

Fonte: Na raça e na cor

Com a preocupação em demonstrar aos ministros, a importância do Decreto $\mathrm{n}^{\circ} 4.887$, a carta explicou a relação de pertença e solidariedade das comunidades com o território, justificando a necessidade de que as terras sejam tituladas.

No documento, as mulheres falaram das ameaças que os quilombos vêm suportando, pela falta de titulação, através de conflitos agrários decorrentes do avanço da fronteira do agronegócio.

\begin{abstract}
"Quem retira o povo de sua terra é perverso e foi assim que fizeram com nossas ancestrais quando as retiraram à força da África e trouxeram para o Brasil, escravizadas. Destruíram famílias, separaram as mães de seus filhos, nos violentaram e massacram a história e cultura de um povo. Ao longo dos séculos de resistência negra no Brasil nós fomos de novo nos juntando, construindo e reconstruindo nossa história. O quilombo é a nossa fortaleza. Não podem retirar tudo isso que construímos com muita luta. Que justiça é essa que tira o pouco que a nossa família conquistou através de muitos anos de luta e resistência?" (Carta das Guerreiras Quilombolas ao STF, 2017 p. 1). ${ }^{8}$
\end{abstract}

Essa carta é a instrumentalização da luta comum que impulsiona o movimento Quilombola, a união de mulheres em favor das Comunidades, um resgate de uma existência e resistência ancestral. Além disso, mundialmente o papel da mulher vem sendo discutido no âmbito dos papéis sociais, econômicos e políticos que elas ocupam. A importância do 
${ }^{8}$ Disponível em: http://naracaenacor.terradedireitos.org.br/files/2017/08/Carta-das-mulheres-quilombolas-aosministros-do-STF_-final-1.pdf. Acesso em: março de 2018. 
reconhecimento é fundamental. Nesse sentido, DeSouza et al(2000, p.485), ressaltam a necessidade de um novo entendimento do papel da mulher.

\begin{abstract}
Pensamos assim por duas razões: 1) As teorias feministas e comunitárias criticam a psicologia tradicional por ser associal e apolítica; isto é, a mulher pobre tem sido silenciada e excluída na teoria e prática psicológica (DeSouza, 1998; Reid, 1993). 2) Embora cada cultura experimente uma realidade social única, nós estamos interligados. Se vivemos no Brasil, na Europa ou nos Estados Unidos, nós vivemos em uma comunidade cada vez mais pluralista devido à imigração, à economia globalizada e aos avanços tecnológicos (p. ex., televisão por satélite, Internet, crescente rede de transporte mundial) que nos ligam através de grandes distâncias (DeSouza, 1998). Especificamente, enquanto a opressão do sexismo parece manifestar-se naturalmente no Brasil, ela ainda assim é vista como opressão em outras culturas. (Hecht \& Baldwin, 1998), como nos Estados Unidos.
\end{abstract}

É na reprodução e construção das relações sociais não dominantes que surgem elementos inovadores capazes de transformar posições hegemônicas. O quilombo é a materialização histórica de resistência do negro. A organização da mulher afro-amazônida se mostra como um projeto de resistência e mudança social concreto que, com espontaneidade e solidariedade revela que o espaço da mulher é de grandeza, determinação e crítica à realidade.

\title{
3 METODOLOGIA
}

A fim de fundamentar essa pesquisa, que se originou a partir de uma dissertação de mestrado, foram realizadas observações das reuniões da FOQS e a análise do documentário "Na raça e na cor". Além disso, uma revisão bibliográfica foi realizada no Google Acadêmico, com busca das palavras-chave "identidade quilombola" e "identidade da mulher quilombola". Também serviram como fonte as bibliografias que tratam do tema em questão, selecionando se os autores constantes do nosso referencial.

\section{CONSIDERAÇÕES FINAIS}

O presente artigo insere-se em um contexto analítico que busca compreender os processos de resistência das Comunidades Quilombolas de Santarém - PA, através da força feminina, envolvendo o elo histórico entre as subjetividades coletivas, abrangendo a relação 
dos atores sociais com a sua história, crenças, práticas ancestrais de existência, resistência e reexistência, diante do avanço da fronteira do agronegócio.

Visualizar a formação socioespacial escravista da Amazônia nos permite identificar uma das africanidades que foram construídas no território brasileiro, pois ao falar sobre o afro-amazônida, verifica- se que o Brasil é um país de várias Áfricas.

O afro-brasileiro em suas múltiplas espacialidades: afro-mineiro, afro-nordestino, afro-paulista, afro-sulista, afro-amazônida, são sujeitos da reconstrução da África no contexto social, econômico e jurídico de cada região e comunidade.

A reconstrução dos lugares e dos papéis da mulher quilombola santarena revela um processo de dupla resistência: a de raça e a de gênero dentro das Comunidades e da Federação Quilombola, por meio da solidariedade entre as mulheres, que protagonizaram mobilizações para ampliação dos padrões de reconhecimento. E mais, quebraram e vem quebrando paradigmas que tem determinado, por séculos, o lugar da mulher no âmbito privado, abrindo espaços e contribuindo para a consolidação de direitos femininos também no espaço público.

As mulheres estão presentes na luta do Movimento Quilombola, com representatividade nas presidências das Comunidades, em cargos de confiança da Federação da Organização dos Quilombolas de Santarém e dos Conselhos Municipais de Saúde e Transporte.

O debate sobre o lugar da mulher no processo de construção de identidade de um povo, assim como os diferentes modos de integração do seu papel no seio das comunidades, revela a necessidade das afro-amazônidas estarem sempre inseridas na luta por melhores condições de existência e reconhecimento e, ainda, a necessidade de que o Estado ampare a luta.

Com a preocupação em demonstrar aos ministros, a importância do Decreto $\mathrm{n}^{\circ} 4.887$, as mulheres das Comunidades Quilombolas de Santarém enviaram uma carta ao Supremo Tribunal Federal explicando a relação de pertença e solidariedade com o território, justificando a necessidade de que as terras sejam tituladas.

No documento, as mulheres falaram das ameaças que os quilombos vêm suportando, pela falta de titulação, através de conflitos agrários decorrentes do avanço da fronteira do agronegócio. Essa carta foi a instrumentalização da luta em comum que impulsiona o movimento Quilombola e a união de mulheres em favor das Comunidades, um resgate de uma existência e resistência ancestral. 
A identidade é construída no processo de afirmação e de luta, possibilitando o reconhecimento do Outro e suas diferenças. As Comunidades Quilombolas não pertencem 
somente a um passado escravista, tampouco se configuram como comunidades isoladas, no tempo e no espaço, sem qualquer participação em nossa estrutura social. A percepção e elaboração de sentido do que somos e de nossas ideias de para onde vamos, perpassam pela teia da cultura e do reconhecimento de um passado de luta e resistência.

A fronteira do agronegócio, que avança na região de Santarém - PA, provoca o embate do desencontro de percepções, tornando o conflito efetivo ao se chocar com os agentes da frente de expansão.

As guerreiras afroamazônidas não podem ser definidas, pois a construção dessa identidade tem por essência a contradição, a diversidade, a necessidade e a luta.

\section{REFERÊNCIAS}

ALMEIDA, Alfredo W. Berno de. Os Quilombos e as Novas Etnias. Manaus, UEA, 2011.

\section{. Territórios e Territorialidades Específicas na Amazônia: Entre A}

"Proteção" e o "Protecionismo". CADERNO CRH, Salvador, v. 25, n. 64, p. 63-71, Jan./Abr. 2012.

ALMEIDA. Lady Christina. Protagonismo e autonomia de mulheres negras, a experiência das organizações. Seminário Internacional Fazendo Gênero 9: Diásporas, Diversidades, Deslocamentos. Florianópolis: Universidade Federal de Santa Catarina, 2010. Disponível em: <File:///C:/Users/renat/Downloads/Ficha_catalogr\%C3\%A1fica_anais_Fazendo\%20Genero_f im.pdf >. Acesso em: março de 2018.

ARRUTI. José Maurício. Quilombos. In: PINHO, Osmundo; SANSONE, Lívio. Raça. Novas Perspectivas antropológicas. Salvador: Associação Brasileira de Antropologia; Edufba, 2008.

Dez anos do Decreto 4887: Dos efeitos de uma política de reconhecimento sobre o campo acadêmico. In https://etnico.wordpress.com/2013/12/01/dezanos-do-decreto-4887-dos-efeitos-de-uma-politica-de-reconhecimento-sobre-o-campoacademico-i/ 
BALDI, César Augusto. A Renovação do Direito Agrário e os Quilombos: Identidade, Território e Direitos Culturais. In Revista da Fac. Dir UFG, v. 37, n. 02, p. 196 - 234, jul.- 
dez, 2013.

BARGAS, J.; CAL, D. Entre lutas por reconhecimento e relações de poder: o papel das mulheres na organização sociopolítica do movimento quilombola no Pará, Brasil. $9^{\circ}$ Congresso Latino America de Ciência Politica, n. 9, p. 1-24, 2017.

BARG, Anderson. Antecipação dos efeitos da tutela relativa a prestações de seguridade social: reversibilidade e necessidade de devolução dos valores recebidos. Revista de Doutrina da $4^{a}$ Região, Porto Alegre, n.73, set. 2016. Disponível em:

<http://revistadoutrina.trf4.jus.br/artigos/edicao073/Anderson_Barg.html> Acesso em: 19 mar. 2018.

BRASIL. Constituição (1988). Constituição da República Federativa do Brasil. Brasília, DF: senado, 1988.

BRASIL. Lei $\mathbf{n}^{\mathbf{0}}$ 4.504, de 30 de novembro de 1964._Dispõe sobre o Estatuto da Terra, e dá outras providências. Disponível em: http://www.planalto.gov.br/ccivil_03/Leis/L4504.htm> Acesso em: 30 nov. 2015.

BRASIL. Proposta de Recomendação no 2 , de 07 de agosto de 2017. Dispõe sobre a atuação do Ministério Público em Políticas Públicas Efetivadoras de Direitos Fundamentais e estabelece diretrizes para a realização ou o referendo de acordos. BRASÍLIA, DF.

DeSouza, et al. A construção social dos papéis sexuais femininos. Psicologia: Reflexão e Crítica, 2000, 13(3), pp.485-496.

FEDERAÇÃO DAS ORGANIZAÇÕES QUILOMBOLAS DE SANTARÉM - FOQS.

Disponível em: http://quilombolasdesantarem.blogspot.com.br/. Acesso em: outubro de 2016.

FUNES. Eurípedes. Bom Jardim, Murumurutuba, Murumuru, Tiningu, Ituqui, Saracura, Arapemã. Terras de Afro-amazonidas - "Nós já somos a reserva, somos os filhos deles". Arquivos UFOPA. 1995. Disponível em:

$<$ http://www.ufopa.edu.br/arquivo/docdiv/2017/bom-jardim-murumurutuba-murumurutiningu-ituqui-saracura-arapema.-terras-de-afro-amazonidas-201cnos-ja-somos-a-reservasomos-os-filhos-deles201d>. Acesso em janeiro de 2017.

GONZALEZ, Lélia. A categoria político-cultural de amefricanidade. In: Tempo Brasileiro. Rio de Janeiro, 1988, p. 69-82. 
. Racismo e sexismo na cultura brasileira. In: Revista Ciências Sociais

Hoje, Anpocs, 1984, p. 223-244.

KLEIN, H. S.; LUNA, F. V. Escravidão Africana - America Latina e Caribe. [s.1.] Editora Brasiliense, 1987.

. Escravos e Senhores no Brasil no Início do Século XIX.

Estudos Econômicos, v. 20, n. 3, p. 349-379, 1991.

. Economia e sociedade escravista: Minas Gerais e São Paulo

em 1830. Revista Brasileira de Estudos de População, v. 21, n. 1984, p. 173-193, 2005.

Evolução da Sociedade e Economia Escravista de São Paulo, de 1750 a 1850. 1. ed. São Paulo: Evolução da Sociedade e Economia Escravista de São Paulo, de 1750 a 1850, 2006.

MAESTRI, M. Silêncio, Marginalização, Superação e Restauração. O Cativo Negro na Historiografia Brasileira. In: EUGÊNIO, J. K. (Ed.). . Escravidão Negra no Piauí e Tema Conexos. Teresina: EDUFPI, 2014. p. 7-52.

PROJETO BRASIL LOCAL ETNODESENVOLVIMENTO E ECONOMIA SOLIDÁRIA. Relatório da Pesquisa Quantitativa em Nove Comunidades Quilombolas de Santarém - Pará. Disponível em: <http://racismoambiental.net.br/wp-content/uploads/2013/11/Relatorio-ParaI-PARTE.pdf $\geq$. Acesso em: outubro de 2016.

REIS, Arthur Ferreira Cesar. Santarém: seu desenvolvimento histórico. $2^{\mathrm{a}}$ edição. Rio de Janeiro: Civilização Brasileira, 1979.

SALLES, Vicente. O negro no Pará, sob o regime da escravidão. Rio de Janeiro, Fundação Getúlio Vargas. Universidade Federal do Pará, 1971.

SCOTT. Rebecca J. O trabalho escravo contemporâneo e os usos da história. Revista Mundos do Trabalho, vol. 5, janeiro-junho de 2013, p. 129-137.

SCOTT, Joan W. Gênero: Uma Categoria Útil de Análise Histórica. IN: Educação e Realidade. Porto Alegre, vol. 20, n. 2, p.71-99, jul/dez. 1995. 
SCHWARCZ, Lilia M. e STARLING, Heloisa M. Brasil: uma biografia. $1^{\text {a }}$ ed. São Paulo: Companhia das Letras, 2015. 
SEGATO. Rita Laura. Gênero e colonialidade: em busca de chaves de leitura e de um vocabulário estratégico descolonial. e-cadernos ces (Online), 2012. Disponível em: < http://eces.revues.org/1533>. DOI: 10.4000/eces.1533. Acesso em: março de 2018.

TARREGA, Maria Cristina Vidotte Blanco \& FRANCO, Rangel Donizete. A Reefetuação das Comunidades Quilombolas em Constituições Contemporâneas, especialmente o item “Afrodescendentes em Constituições Latinoamericanas”. In Revista Crítica do Direito, n. 3 , vol. 54, 2013, p. 1-19.

TAVARES. Maria Goretti da Costa. A Formação Territorial do Espaço Paraense: Dos Fortes à Criação de Municípios. Universidade Federal do Pará Revista ACTA Geográfica, ANO II, n³, jan./jun. de 2008. p.59-83.

THOMPSON, Edward Palmer. As peculiaridades dos ingleses e outros artigos. São Paulo: Unicamp, 2001. 372 p.

WALKER, S. S. Presencia de la diáspora africana en toda América y en todos los americanos, desde Argentina a Canadá. In: De la cadena al vínculo. Una visión de la trata de esclavos. PARIS: UNESCO, 2001. p. 359-366. 